\title{
Gaseous phase benzene decomposition by non-thermal plasma coupled with nano titania catalyst
}

\author{
${ }^{1}$ T. Zhu; ${ }^{1 *}$ J. Li; ${ }^{1}$ Y. Q. Jin; ${ }^{2}$ Y. H . Liang; ${ }^{2}$ G. D. Ma \\ ${ }^{1}$ College of Environmental and Energy Engineering, Beijing University of Technology, \\ Beijing 100124, China \\ ${ }^{2}$ Department of Environmental Engineering, Xi'an University of Architecture and Technology, \\ Xi'an 710055, China
}

Received 21 July 2008; ～revised 9 August 2008; accepted 24 November 2008; available online 10 December 2008

\begin{abstract}
Synergistic effect of atmospheric non-thermal plasma generated by dielectric barrier discharge and nano titania photocatalyst for benzene decomposition was tested. The paper indicated the effect of photocatalyst on removal efficiency of benzene, the compare of photocatalyst characteristic in different high temperatures by heat treatment, analysis of by-products. The results showed that the effect of degradation was visible by added photocatalyst in the plasma reactor. When concentration of benzene was $600 \mathrm{mg} / \mathrm{m}^{3}$ and electric field strength was $10 \mathrm{kV} / \mathrm{cm}$, the removal efficiency of benzene was increased up to $81 \%$ without photocatalyst. At the same condition, the removal efficiency was increased to $15 \%$ higher with photocatalyst. Nano titania crystal was anatase crystal in $450{ }^{\circ} \mathrm{C}$ heat treatment which is best for benzene removal. The plasma reactor packed with photocatalyst shows a better selectivity of carbon dioxide than that without photocatalyst. By-products are mostly carbon dioxide, water and a small quantity of carbon monoxide.
\end{abstract}

Key words: Dielectic barrier discharge, removal efficiency, anatase, carbon dioxide

\section{INTRODUCTION}

As an emerging technology for environmental protection, there have been extensive researches on using non-thermal plasma (NTP) over the past 20 years (Tonkyn et al.,1996; Futamura et al., 1997; Muhamad and Jiang, 2000; Zhu et al., 2008a). The major advantages of NTP technology include the moderate operation conditions (normal temperature and atmospheric pressure), moderate capital cost, compact system, easy operations and short residence times, etc. compare to the conventional technologies (Magureanu et al., 2005; Zhu et al., 2008b). In the field of air pollution control, the NTP technology has been tested for the abatement of various types of hazardous air pollutants such as volatile organic compounds (VOCs) (Ogata et al., 1999; Urashima and Chang, 2000; Futamura et al., 2004; Magureanu et al., 2007; Subrahmanyam et al., 2007), $\mathrm{SO}_{2}$ (Mizuno, et al.,1986; Changet al.,1991), NOx (Ohkubo et al.,1994; Tonkyn et al.,2003; Young et al., 2004), CFCs (Li and Ma, 2000; Gal et al., 2003; Park et al., 2003; Ricketts et al., 2004) odors

*Corresponding Author Email: lj@bjut.edu.cn Tel: +86 106739 2080; Fax: +86 1067392080
(Masuda et al., 1993; Mizuno et al.,1993; Chang and Tseng, 1996; Zhu et al., 2007), mercury (Masuda,1988), etc. In order to further improve the energy efficiency of the VOCs removal decomposition process by the plasma, the cooperation with catalyst has been tested by some researchers (Einaga et al., 2001; Guo et al., 2006; Kim, 2006; Kim etal., 2008). These studies showed that the combination of discharge plasma with catalyst is a very effective method in VOCs removal. In this paper, non-thermal plasma coupled with nanotitania $\left(\mathrm{TiO}_{2}\right)$ photocatalyst for benzene removal to further reduce the energy consumption and harmful byproducts in plasma process. Discharge plasma as a driving force of photocatalyst furnished a mess of UV light. Hole-electron pairs are produced by supplying energy larger than the band gap energy of $\mathrm{TiO}_{2}(3.2 \mathrm{eV}$ for anatase type). High energy particles such as electrons, excited molecules and radicals may transfer their energy to $\mathrm{TiO}_{2}$ by bombardment when $\mathrm{TiO}_{2}$ is placed in a non-thermal plasma.

Various chemical reactions are induced on the excited $\mathrm{TiO}_{2}$ surface through the following reactions: 


$$
\begin{aligned}
& \mathrm{TiO}_{2}+\text { Plasma } \rightarrow h^{+}+e^{-} \\
& h^{+}+\mathrm{H}_{2} \mathrm{O} \rightarrow \mathrm{OH}+\mathrm{H}^{+} \\
& e^{-}+\mathrm{O}_{2} \rightarrow \mathrm{O}_{2}^{-} \\
& e^{-}+\mathrm{H}_{2} \mathrm{O}_{2} \rightarrow \mathrm{OH}+\mathrm{OH}^{-} \\
& \mathrm{O}_{2}^{-}+\mathrm{H}^{+} \rightarrow \mathrm{HO}_{2} \\
& \text { Radicals }+ \text { Reactant } \rightarrow \text { Products }
\end{aligned}
$$

This paper illuminates the experimental results of the synergistic effect of NTP generated by dielectric barrier discharge (DBD) and nano- $\mathrm{TiO}_{2}$ catalyst on benzene decomposition. The results showed that the effect of degradation was visible by added photocatalyst in the plasma reactor. The removal efficiency of benzene was increased to $98 \%$ with benzene concentration of $600 \mathrm{mg} / \mathrm{m}^{3}$ and electric field strength of $10 \mathrm{kV} / \mathrm{cm}$. At the same time, a better selectivity of carbon dioxide of $60 \%$ was given.

The reaction activity of anatase catalyst is higher than that of rutileat catalyst. Above all that means this technology of NTP coupled with nano- $\mathrm{TiO}_{2}$ (anatase) would have a great potential for application in the future.

\section{MATERIALS AND METHODS}

\section{Experimental system}

The reaction system was a tube-wire packed-bed reaction system at atmospheric pressure. The schematic diagram of NTP system is shown in Fig. 1. Dry air (78 \% $\mathrm{N}_{2}, 21 \% \mathrm{O}_{2}$ ) was used as a balance gas for benzene decomposition. Air supplied from air compressor was divided into two air flows. Each flow rate was controlled with a mass flow meter.

One air flow was introduced into 3 benzene liquid bottle which contained liquid benzene. The air with a mass of saturated vapor of benzene was mixed with the other air flow in 4 blenders and gaseous phase benzene was diluted to a prescribed concentration. A wire-tube DBD reactor with catalyst in situ was used in the reaction as shown in Fig. 2.

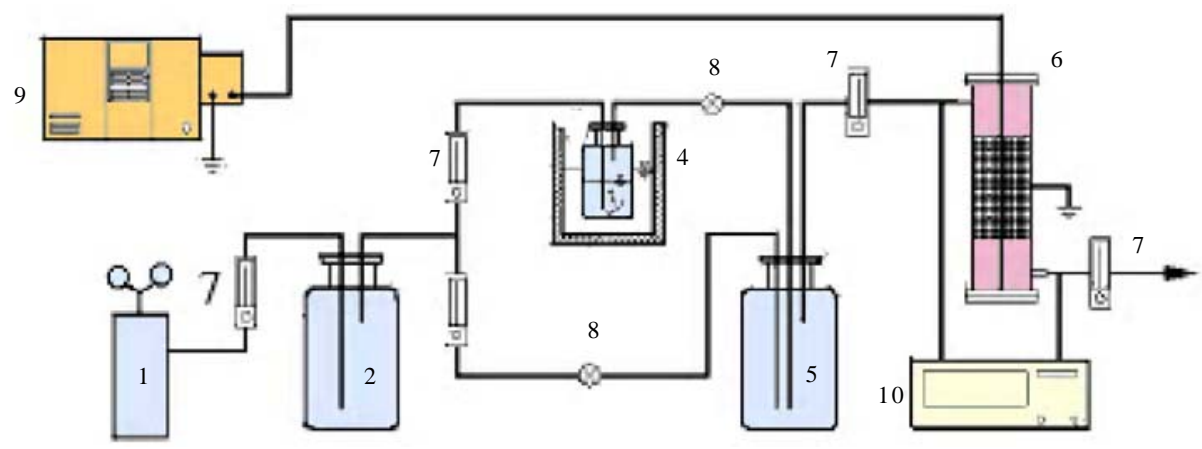

1. Air compressor, 2. Buffer, 3. Liquid bottle of benzene, 4. Attemperator, 5. Blender, 6. NTP reactor, 7. Flow-meter, 8. Valve, 9. High voltage, 10. GC

Fig. 1: Schematic diagram of NTP system for benzene removal

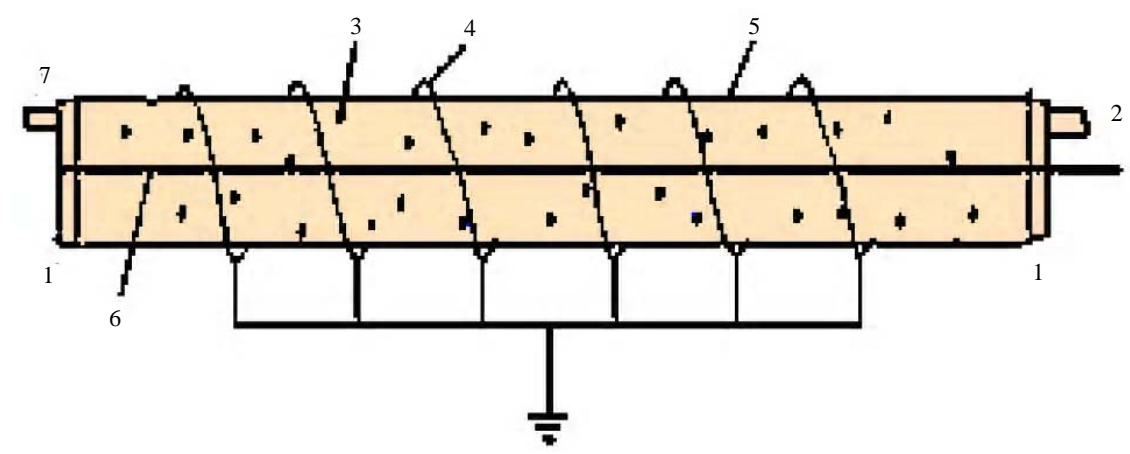

1. Plug, 2. Inlet, 3. Packed materials, 4. Outer electrode, 5. Insulated tube, 6. Axes electrode, 7. Outlet

Fig. 2: Tube wire reactor of DBD 


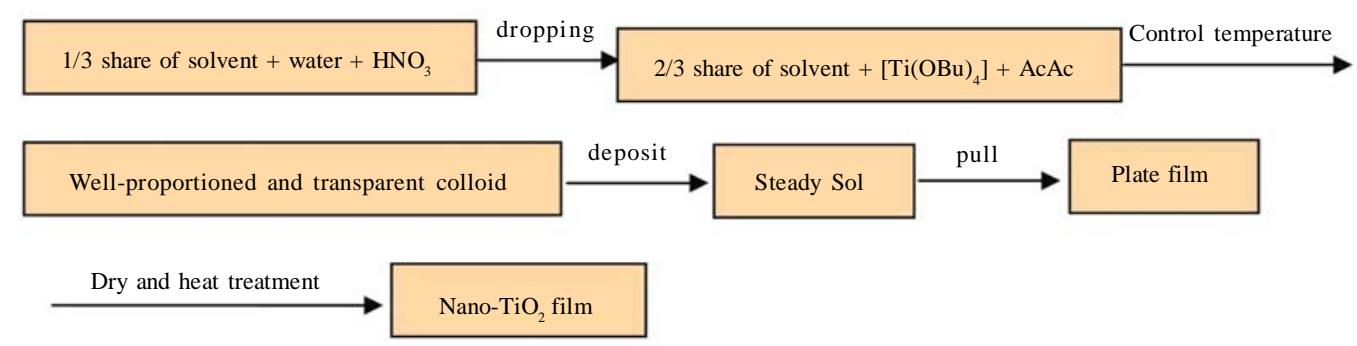

Fig. 3: Flow chart on preparing nano- $\mathrm{TiO}_{2}$ thin film by Sol-Gel method

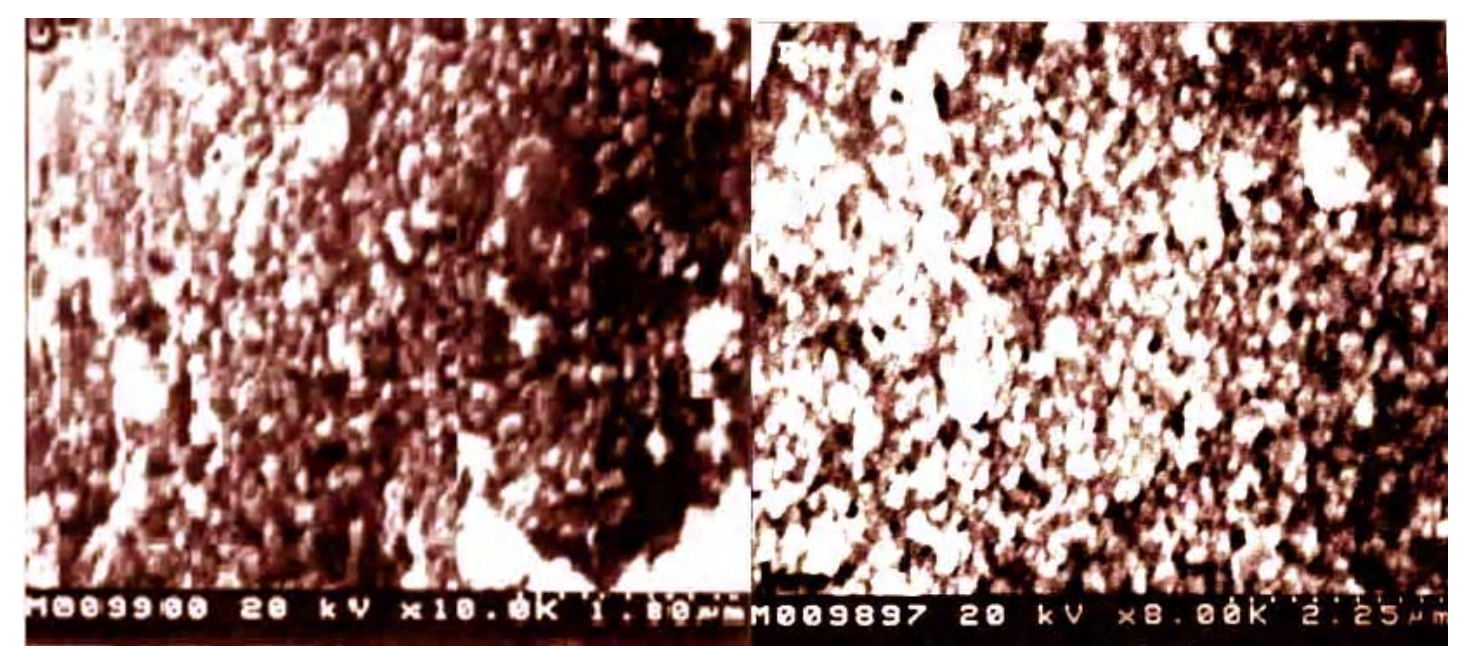

Fig. 4: SEM micrograph of $\mathrm{TiO}_{2}$

A packed reactor with coaxial electrodes was designed as illustrated in Fig. 2.

The packed materials (i.d. $5 \mathrm{~mm}$, length $10 \mathrm{~mm}$, rasching ring) coated with nano- $\mathrm{TiO}_{2}$ photocatalyst were packed into the reactor. The reactor were made of ceramic tube (i.d. $50 \mathrm{~mm}$, reaction length $500 \mathrm{~mm}$ ), axes electrode (i.d. $1.5 \mathrm{~mm}$, stainless steel wire), outer electrode (80 circles stainless steel wire). The characteristic of packed materials includes volume density $217 \mathrm{~g} / \mathrm{cm}^{3}$, hole rate $12.7 \%$ and bibulous $5.9 \%$.

Nano- $\mathrm{TiO}_{2}$ films were prepared by the Sol-Gel method (Liang, et al., 2006) in the experiment. Flow chart on preparing nano- $\mathrm{TiO}_{2}$ thin film by SolGel method referred to Fig.3.

The nanometer $\mathrm{TiO}_{2}$ thin film was inspected and analyzed by scan electric mirror (SEM, Made in Japan, S-2700).
The results of SEM micrograph showed that average particulate diameters of $\mathrm{TiO}_{2}$ were less than $100 \mathrm{~nm}$. SEM micrograph of the samples referred to Fig. 4.

The plasma reactor employed an alternating current (AC) power supply of $60 \mathrm{~Hz}$ (designed by the authors). The AC voltage was applied to the reactor in the radial direction and the AC voltage extension lied from $0 \mathrm{kV}$ to $30 \mathrm{kV}$. The benzene concentration was determined on a gas chromatography (manufactured by American Thermo Finnigan Co.TRACE-GC ULTRA) with a flame ionization detector (FID) and a capillary column of DB-1. Separately, another GC (SC - 1001) equipped with an FID detector and an methane converter was used to analyze concentration of $\mathrm{CO}_{2}$ and $\mathrm{CO}$. Reaction gas samples were taken by a syringe from the sampling ports of the reactor.The by-products were identified by GC-MS with a $30 \mathrm{~m}$ long wide bore capillary column 

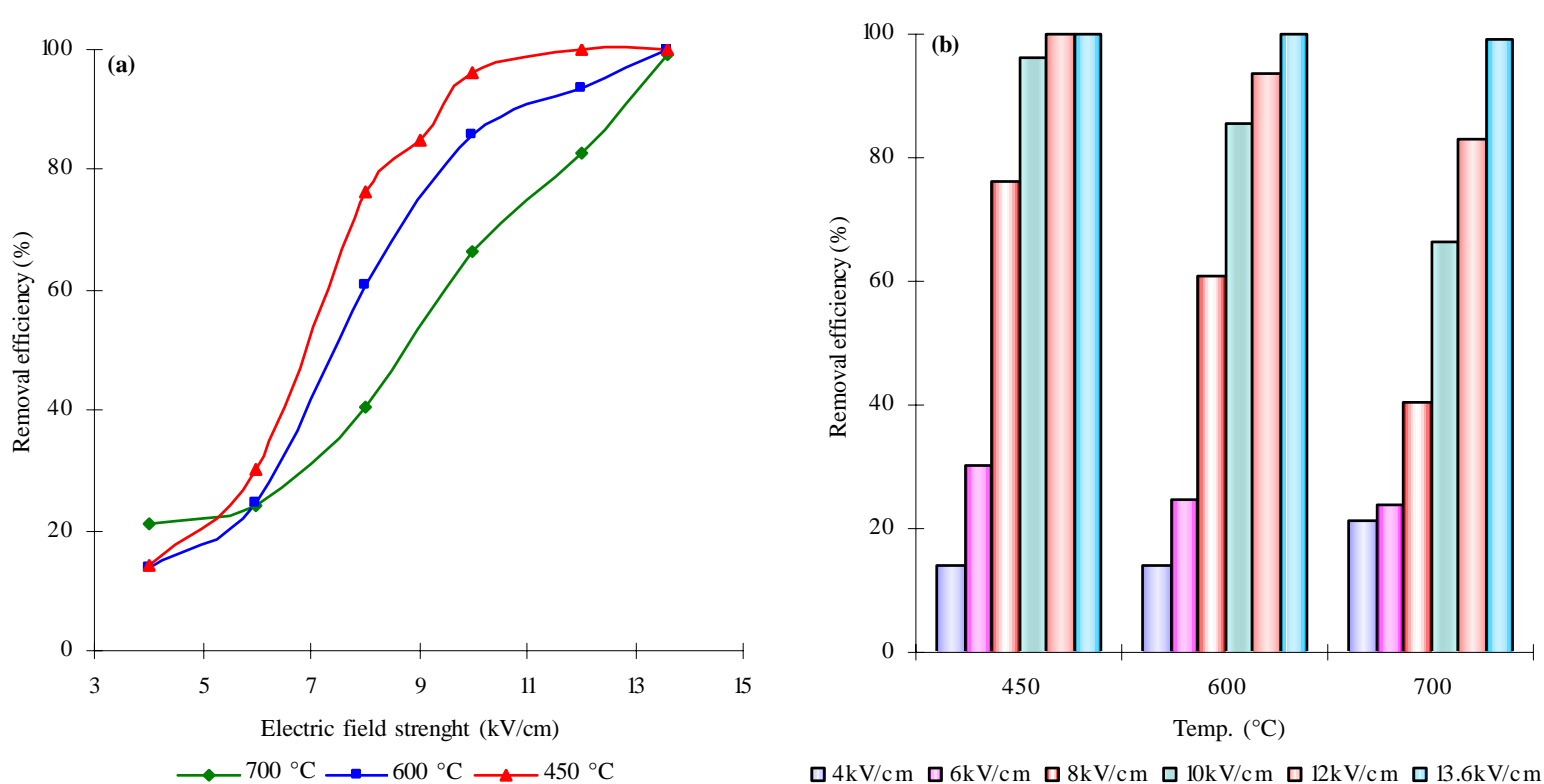

Fig. 5: Compare with catalyst characteristic of different treatment temperature

(DB-1). The experimental condition was in atmospheric pressure $(760 \mathrm{mmHg})$ and temperature $\left(20^{\circ} \mathrm{C}\right)$.

\section{RESULTS AND DISCUSSION}

The Fompare of photocatalyzed characteristic by different heat treatment

The packed materials with photocatalyst were to calcine at $450^{\circ} \mathrm{C}, 600^{\circ} \mathrm{C}$ and $700^{\circ} \mathrm{C}$ in the muffle. Then, they were packed into the plasma reactor. The samples of packed materials were detected by X-Ray and testified that nano- $\mathrm{TiO}_{2}$ was anatase at $450{ }^{\circ} \mathrm{C}$ and nano- $\mathrm{TiO}_{2}$ was mixture of anatase and rutileat at $600{ }^{\circ} \mathrm{C}$ and nano- $\mathrm{TiO}_{2}$ was rutile mostly at $700{ }^{\circ} \mathrm{C}$. The experimental results are shown in Fig. 5.

The decomposition efficiency of benzene is best with anatase photocatalyst in the plasma reactor. Next, the decomposition efficiency is better with the mixture photocatalyst of anatase and rutileat and the last to rutileat photocatalyst. The above all are shown in Figs. $5 \mathrm{a}$ and $\mathrm{b}$ which show the decomposition efficiency of benzene reduction, gradually when the packed materials with photocatalyst by heat treatment from $450{ }^{\circ} \mathrm{C}$ to $700{ }^{\circ} \mathrm{C}$. On one hand, when sinter temperature is raised, the surface areas of catalyst reduce and the surface adsorption capacity decrease. On the other hand, nano$\mathrm{TiO}_{2}$ catalyst will transform from anatase to rutileat. In Fig. 5 a, the test shows the reaction activity of anatase catalyst is higher than that of rutileat catalyst. There are four reasons:

- Because of structural difference, two type of catalyst have different quality densities and different structure of energy gap of electron. The quality density of anatase of $3.894 \mathrm{~g} / \mathrm{cm}^{3}$ is less than that of rutileat of $4.250 \mathrm{~g} / \mathrm{cm}^{3}$. The energy of energy gap of anatase which is $3.2 \mathrm{eV}$ is higher than that of rutileat which is $3.1 \mathrm{eV}$. The higher energy of energy gap leads to the higher reaction activity for catalyst.

- The surfaces of anatase possess symmetrical structure with the molecular structure of benzene. Thus, it can adsorb benzene effectively.

- The hydroxyl of surface of rutileat is not more than that of anatase. Since the hydroxyl of surface is helpful for benzene removal, anatase is better than rutileat on benzene degradation.

- The surface area of rutileat catalyst declines sharply because a large number of particles converge under high temperature. The adsorption capacity of rutileat of $\mathrm{TiO}_{2}$ is not proper for $\mathrm{O}_{2}$. Thus, catalyst activity is low and nano- $\mathrm{TiO}_{2}$ photocatalyst of anatase crystal was employed for next experiment.

The Effect of photocatalyst on removal efficiency of benzene

The relationship between benzene degradation and 

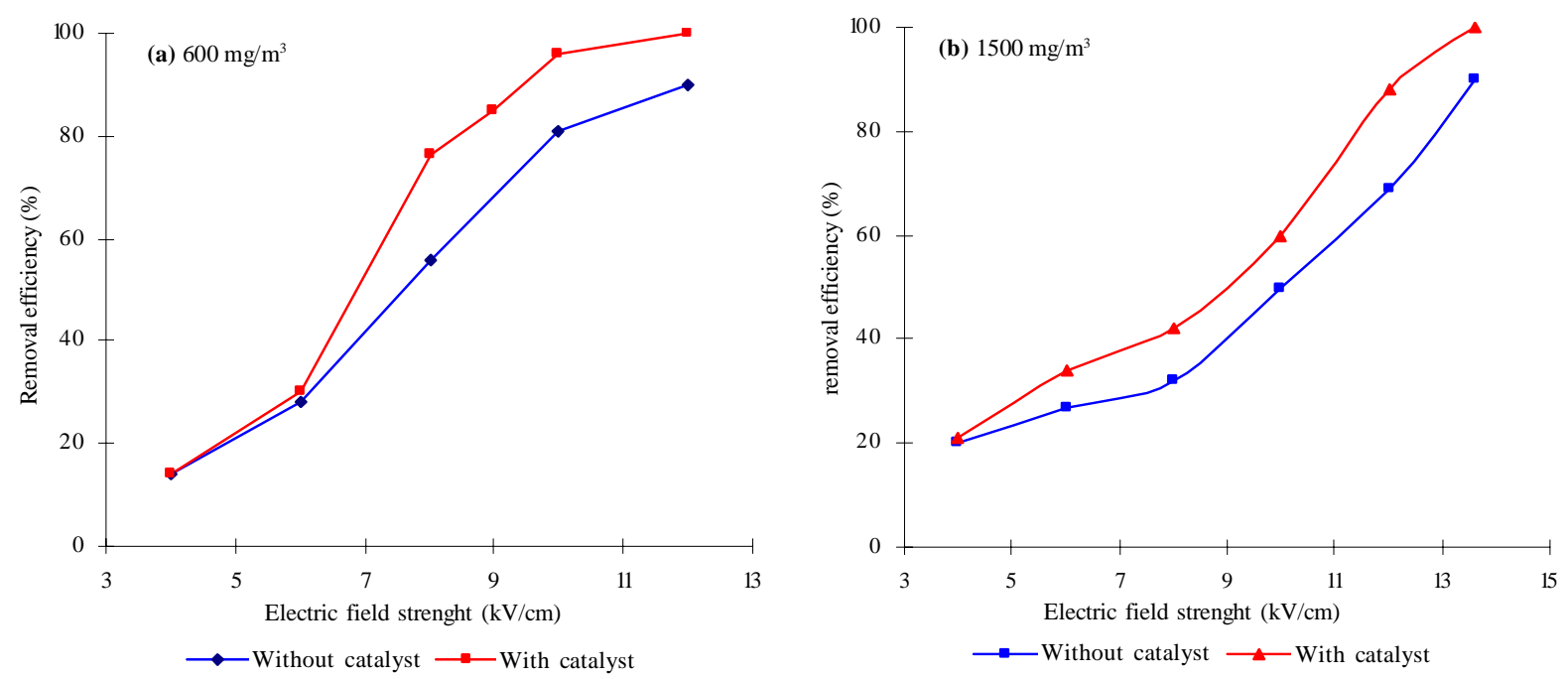

Fig. 6: Relationship between benzene removal and electric field strength with or without catalyst

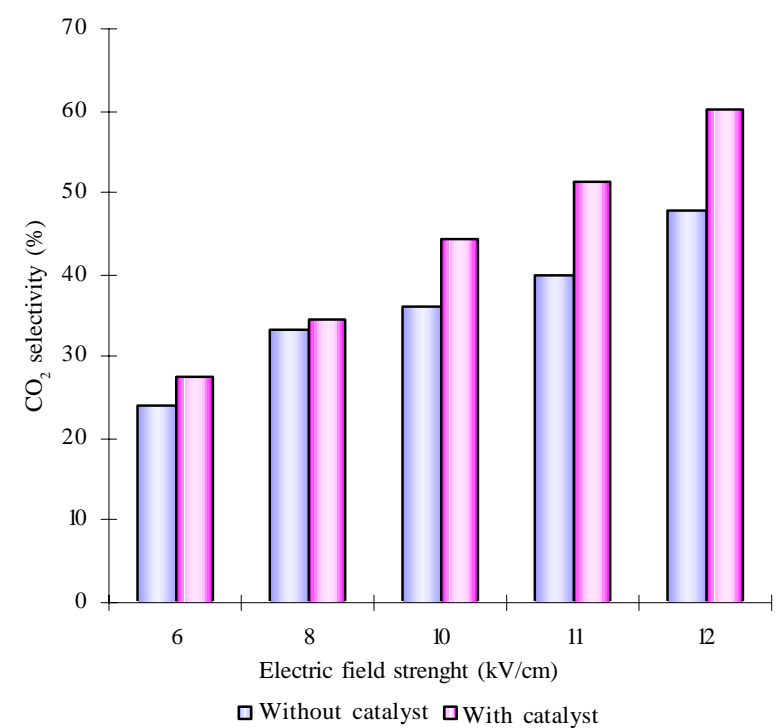

Fig. 7: $\mathrm{CO}_{2}$ selectivity with or without catalyst $\left(1500 \mathrm{mg} / \mathrm{m}^{3}\right)$

electrostatic field strength with or without catalyst is shown in Fig. 6 (benzene concentration: 600-1500 $\left.\mathrm{mg} / \mathrm{m}^{3}\right)$.

The removal efficiency of benzene is $98 \%$ in the reactor with catalyst while the removal efficiency of benzene is $78 \%$ in the reactor without catalyst with concentration of $600 \mathrm{mg} / \mathrm{m}^{3}$, electric field strength of $10 \mathrm{kV} / \mathrm{cm}$ and gas flow rate of $14 \mathrm{~mm} / \mathrm{s}$ as shown in Fig. 6 a. The removal efficiency with catalyst is $19 \%$

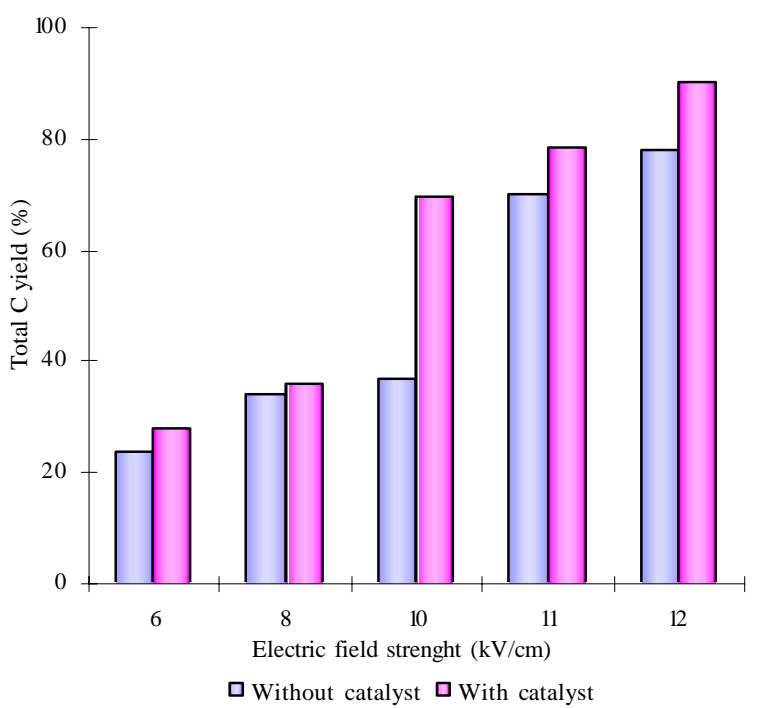

Fig. 8: Total C yield with or without catalyst $\left(1500 \mathrm{mg} / \mathrm{m}^{3}\right)$

higher than without catalyst with concentration of $1500 \mathrm{mg} / \mathrm{m}^{3}$, electric field strength of $12 \mathrm{kV} / \mathrm{cm}$ and gas flow rate of $14 \mathrm{~mm} / \mathrm{s}$ as shown in Fig. $6 \mathrm{~b}$. Obviously, the results indicate that catalyst enhanced the removal efficiency.

By-products analysis

Complete oxidation of benzene to $\mathrm{CO}_{2}$ is the final goal of the experiment and the catalytic effect on the product 


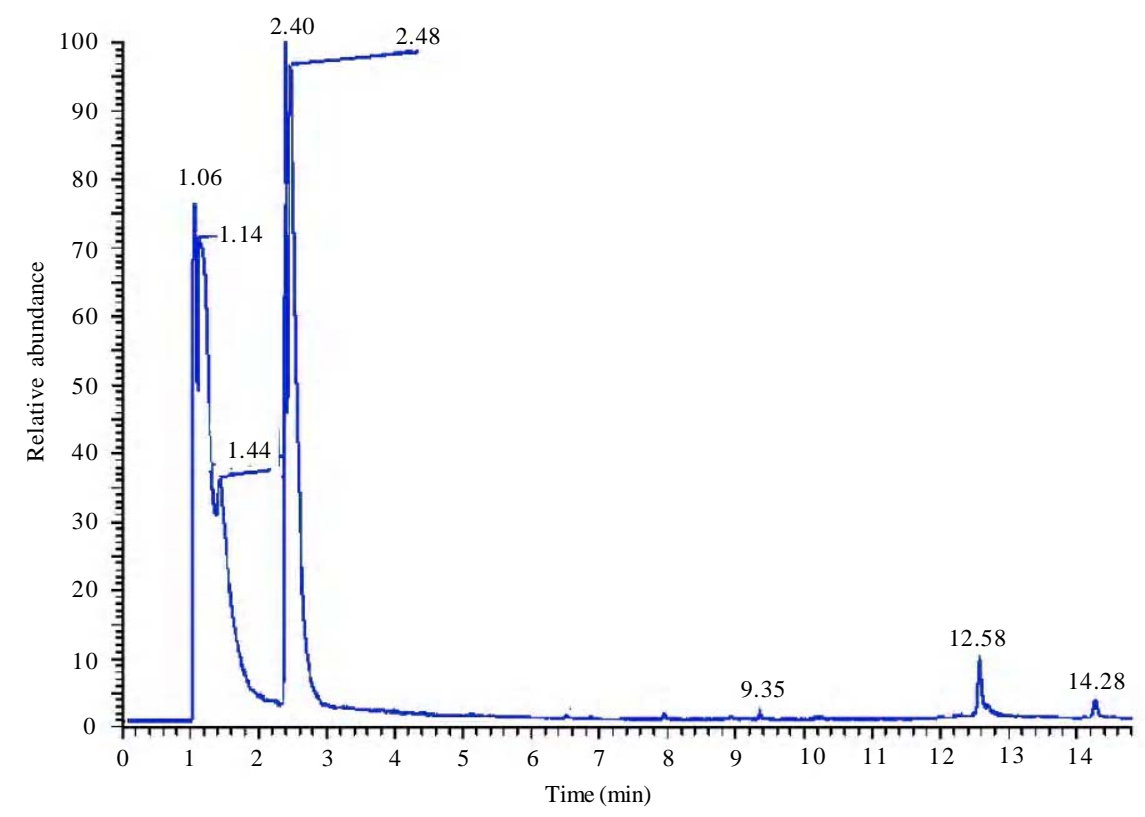

Fig. 9: By-products graph of GC-MS

distribution had been investigated. Photo-oxidation activity should be expressed as selectivity to $\mathrm{CO}_{2}$ because other by-products except $\mathrm{CO}_{2}$ were emitted in plasma process.

Here, the selectivity of $\mathrm{CO}_{2}$ was calculated as follow:

$$
\mathrm{CO}_{2} \text { selectivity }(\%)=\frac{\left[\mathrm{CO}_{2}\right]}{6\left([\text { Benzene }]_{0}-[\text { Benzene }]\right)} \times 100
$$

Where, the [Benzene] $]_{0}$ and [Benzene] indicate inlet and outlet concentrations of benzene, respectively. Though GC-MS, the main products in the plasma reactor were $\mathrm{CO}_{2}, \mathrm{H}_{2} \mathrm{O}$ and a small quantity of $\mathrm{CO}$. Ozone was the only byproduct and no other by-products could be detected in the tail gas. In addition, certain brown-yellow products that were observed in the plasma reactor regardless of with or without catalyst appeared in Fig. 9.

The composition of the brown-yellow products was indistinct and maybe it was aromatic polymer detected by GC-MS. From Fig. 7, it is found the selectivity of $\mathrm{CO}_{2}$ ranges from $24 \%$ to $48 \%$ in the plasma reactor without catalyst while the selectivity of $\mathrm{CO}_{2}$ ranges from $28 \%$ to $60 \%$ in the reactor with catalyst. The selectivity of $\mathrm{CO}_{2}$ is enhanced due to the benzene oxidation near or on the catalyst surface. For that, it could be thought that intermediates and secondary products are more oxidized to $\mathrm{CO}_{2}$ on catalyst surface. With benzene concentration increasing, the total output of $\mathrm{C}$ increases as shown in Fig. 8.

Therefore, the hybrid system comprising a nonthermal plasma reactor and nano- $\mathrm{TiO}_{2}$ catalyst, not only in the gas phase, but also on the catalyst surface resulted in the higher energy efficiency and enhanced performance for the oxidative removal of benzene with lower medium reactivity and higher $\mathrm{CO}_{2}$ selectivity in non-thermal plasma.

\section{CONCLUSION}

Four important results were obtained experimentally. - Photocatalyst enhanced the benzene decomposition efficiency obviously. The benzene removal by the nonthermal plasma without photocatalyst was not as good as that by the non-thermal plasma with it. When electrostatic field strength arrived at $10 \mathrm{kV} / \mathrm{cm}$ in the plasma reactor, benzene decomposition level of higher than $98 \%$ was obtained. Although, the initial benzene concentration was low, i.e. $600 \mathrm{mg} / \mathrm{m}^{3}$ in the dry air. At the same time, benzene decomposition efficiency increased with increasing electrostatic field strengths. - Nanometer $\mathrm{TiO}_{2}$ took on anatase by heat treatment of $450{ }^{\circ} \mathrm{C}$ and behaved most effective on benzene degradation. 
- It is facile and promising to simultaneously hybridize plasma with $\mathrm{TiO}_{2}$ based on the data presented in this paper. The plasma reactor packed with catalyst shows a better selectivity of $\mathrm{CO}_{2}$ than that without catalyst. Detected by GC-MS, the main products in the plasma reactor are $\mathrm{CO}_{2}, \mathrm{H}_{2} \mathrm{O}$ and a small quantity of CO. There are no other products detected in the tail gas.

\section{ACKNOWLEDGEMENTS}

This work was supported by Research Fund for the Doctoral Program of Higher Education of China and Funding Project for Academic Human Resources Development in Institutions of higher learning under the jurisdiction of Beijing municipality.

\section{REFERENCES}

Chang, M. B.; Balbach, J. H.; Rood, M. J.; Kushner, M. J., (1991). Removal of $\mathrm{SO}_{2}$ from gas streams using a dielectric barrier discharge and combined plasma photolysis., J. Appl. Phys., 69 (8), 4409-4418.

Chang, M. B.; Tseng, T. D., (1996). Gas-phase removal of $\mathrm{H}_{2} \mathrm{~S}$ and $\mathrm{NH}_{3}$ with dielectric barrier discharges., J. Environ. Eng., 122 (1), 41-46.

Einaga, H.; Lbusuki, T.; Futamura, S., (2001). Performance evaluation of a hybrid systems comprising silent discharge plasma and manganese oxide catalysts for benzene decomposition., IEEE T. Ind. Appl., 37 (5), 858-863.

Futamura, S.; Einaga, H.; Kabashima, H.; Lee, Y. H., (2004). Synergistic effect of silent discharge plasma and catalysts on benzene decomposition., Catal. Today, 89 (1-2), 8995.

Futamura, S.; Zhang, A. H.; Yamamoto, T., (1997). The dependence of non-thermal plasma behavior of VOCs on their chemical structures., J. Electrostat., 42 (1-2), 51-62.

Gal, A.; Ogata, A.; Futamura, S.; Mizuno, K., (2003). Mechanism of the dissociation of chlorofluorocarbons during non-thermal plasma processing in nitrogen at atmospheric pressure., J. Phys. Chem. A, 107 (42), 88598866.

Guo, Y. F.; Ye, D. Q.; Chen, K. F., (2006). Toluene decomposition using a wire-plate dielectric barrier discharge reactor with manganese oxide catalyst in situ., J. Mol. Catal. A-Chem., 245 (1-2), 93-100.

Kim, H. H.; Ogata, A.; Futamura, S., (2006). Effect of different catalysts on the decomposition of VOCs using flow-type plasma-driven catalysis., IEEE T. Plasma Sci., 34 (3), 984-995.

Kim, H. H.; Ogata, A.; Futamura, S., (2008). Oxygen partial pressure-dependent behavior of various catalysts for the total oxidation of VOCs using cycled system of adsorption and oxygen plasma., Appl. Catal. B-Environ., 79 (4), 356-367.

Li, J.; Ma, G. D., (2000). The mechanismic analysis and experiment on controlling volatile organic compounds (VOCs) with corona discharge., J. Xi'an U. Architecture
Tech., 32 (1), 24-27.

Liang, Y. H.; Zhu, T.; Ma, G. D., (2006). Study of nano$\mathrm{TiO}_{2}$ thin film derived by sol-gel process., J. Xi'an U. Architecture Tech., 38 (6), 799-803.

Magureanu, M.; Mandache, N. B.; Hu, J. C.; Richards, R.; Florea, M.; Parvulescu, V. I., (2005). Plasma-assisted catalysis for volatile organic compounds abatement., Appl. Catal. B-Environ., 61 (1-2), 12-20.

Magureanu, M.; Mandache, N. B.; Parvulescu, V. I.; Subrahmanyam, C.; Renken, A.; Kiwi Minsker, L., (2007). Improved performance of non-thermal plasma reactor during decomposition of trichloroethylene: Optimization of the reactor geometry and introduction of catalytic electrode., Appl. Catal. B-Environ., 74 (3-4), 270-277.

Masuda, S., (1988). Pulse corona induced plasma chemical process: a horizon of new plasma chemical technologies., Pure Appl. Chem., 60 (5), 727-731.

Masuda, S.; Hosokawa, S.; Tu, X. L.; Tsutsumi, M.; Ohtani, T.; Tsukahara, T.; Matsuda, N., (1993). The performance of an integrated air purifier for control of aerosol, microbial, and odor., IEEE T. Ind. Appl., 29 (4), 774-780.

Mizuno, A.; Clements, J. S.; Davis, R. H., (1986). A method of the removal of sulfur dioxide from exhaust gas utilizing pulsed streamer corona for electron energization., IEEE T. Ind. Appl., 22 (3), 516-522.

Mizuno, A.; Yamazaki, Y.; Obama, S.; suzuki, E.; Okazaki, k.; (1993). Effect of voltage waveform on partial discharge in ferroelectric pellet layer for gas cleaning., IEEE T. Ind. Appl., 29 (2), 262-267.

Muhamad, A. M.; Jiang, X. Z., (2000). Catalyst assisted destruction of trichloro ethylene and toluene in corona discharges., J. Environ. Sci., 12 (1), 7-11.

Ogata, A.; Yamanonchi, K.; Mizuno, K., (1999). Decomposition of benzene using alumina-hybrid and catalyst-hybrid plasma reactors., IEEE T. Ind. Appli., 35 (6), 1289-1295.

Ohkubo, T.; Kanazawa, S.; Nomoto, Y.; Jen shih, C.; Adachi, T., (1994). NO removal by a pipe with nozzle-plate electrode corona discharge system., IEEE T. Ind. Appl., 30 (4), 856-861.

Park, J. Y.; Jung, J. G.; Kim, J. S.; Rim, G. H.; Kim, K. S., (2003). Effect of non-thermal plasma reactor for CF decomposition., IEEE T. Plasma Sci., 31 (6), 1349-1354.

Ricketts, C. L.; Wallis, A. E.; Whitehead, J. C.; Zhang, K., (2004). A mechanism for the destruction of CFC-12 in a non-thermal, atmospheric pressure plasma., J. Phys. Chem. A, 108 (40), 8341-8345.

Subrahmanyam, C.; Renken, A.; Kiwi Minsker, L., (2007). Novel catalytic non-thermal plasma reactor for the abatement of VOCs., Chem. Eng. J., 134 (1-3), 78-83.

Tonkyn, R. G.; Barlow, S. E.; Hoard, J., (2003). Reduction of $\mathrm{NO}_{\mathrm{x}}$ in synthetic diesel exhaust via two-step plasmacatalytsis treatment., Appl. Catal. B-Environ., 40 (3), $207-$ 217.

Tonkyn, R. G.; Barlow, S. E.; Orlando, T. M., (1996). Destruction of carbon tetrachloride in a dielectric barrier/ packed-bed corona reactor., J. Appl. Phys., 80 (9), 4877 4886.

Urashima, K.; Chang, J., (2000). Removal of volatile organic compounds from air streams and industrial flue gases by 
non-thermal plasma technology., IEEE T. Dielect. El. In., 7 (5), 602-614.

Young, S. M.; Mirosław, D.; Jerzy, M., (2004). Effect of reaction temperature on NOx removal and formation of ammonium nitrate in non-thermal plasma process combined with selective catalytic reduction., IEEE T. Plasma Sci., 32 (3/2), 799-807.

Zhu, T.; Li, J.; Dou, B. J.; Liang, W. J.; Jin, Y. Q., (2007). Study on treatment tobacco odor with non-thermal plasma technology., J. Xi'an U. Architecture Tech., 39 (6), 862 866.
Zhu, T.; Li, J.; Liang, W. J.; Dou, B. J.; Jin, Y. Q., (2008). Research progresses in treatment of waste gas containing volatile organic compounds by combined plasma technology., Environ. Prot. Chem. Ind., 28 (2), 121-125.

Zhu, T.; Li, J.; Jin, Y. Q.; Liang, Y. H.; Ma, G. D., (2008). Decomposition of benzene by non-thermal plasma processing-photocatalyst and ozone effect., Int. J. Environ. Sci. Tech., 5 (3), 375-384.

\section{AUTHOR (S) BIOSKETCHES}

Zhu, T., M. Sc., Ph.D. research student in air pollution control, College of Environmental and Energy Engineering, Beijing University of Technology, Beijing, China. Email: bamboozt@sohu.com

Li, J., Ph.D., Professor in environmental engineering, College of Environmental and Energy Engineering, Beijing University of Technology, Beijing, China. Email: ljian@bjut.edu.cn

Jin, Y. Q., Professor in environmental engineering, College of Environmental and Energy Engineering, Beijing University of Technology, Beijing, China. Email: jinyq@bjut.edu.cn

Liang, Y. H., Ph.D., Professor, Department of Environmental Engineering, Xi' an University of Architecture and Technology, Xi' an, China. Email: lyah@xauat.edu.cn

Ma, G. D., Professor in environmental engineering, Department of Environmental Engineering, Xi' an University of Architecture and Technology, Xi'an, China. Email: mgd@xauat.edu.cn

This article should be referenced as follows:

Zhu, T.; Li, J.; Jin, Y. Q.; Liang, Y. H.; Ma, G. D., (2008). Gaseous phase benzene decomposition by nonthermal plasma coupled with nano titania catalyst. Int. J. Environ. Sci. Tech., 6 (1), 141-148. 